\title{
NÄYTTELIJÖIDEN KUOLLEISUUS
}

\section{Johdanto}

Kulttuurin, yhteisöllisyyden ja sosiaalisen toiminnan on havaittu vaikuttavan positiivisesti hyvinvointiin, elämänlaatuun ja elinikään (Hyyppä \&t Liikanen 2005, Hyyppä 2013). Kulttuurikuntoilua harrastava voi paremmin ja elää keskimäärin kahdesta kolmeen vuoteen pidempään kuin muut (Hyyppä 2013, 20). Ruotsalaisessa tutkimuksessa havaittiin jo 1990-luvulla kulttuuria harrastavien terveyden olevan parempi ja elinajanodotteen pidempi verrattuna niihin, jotka välttävät sosiaalista kanssakäymistä ja kulttuurillista yhteisöllisyyttä (Bygren ym. 1996). Samanlaisia tutkimustuloksia on saatu myös Ruotsissa, Norjassa, Englannissa ja Amerikassa (Konlaan ym. 2000, Johansson ym. 2001, von Otter 2008, Dalgard \&t Lund Håheim 1998, Willcox ym. 2007, Wilkinson ym. 2007, Glass ym. 1999).

Näyttelijän työ on yhteisöllistä ja luovaa. Näyttelijä kollegoineen tulkitsee sekä yksin että yhdessä tekstiä ohjaajan vision ja kokonaisnäkemyksen mukaan. Teatterin on havaittu vaikuttavan myönteisesti henkiseen hyvinvointiin, koska se taidemuotona "imitoi" ihmiselämän perustoimintoja, on yhteisöllinen, sosiaalinen ja vuorovaikutuksellinen (Emunah 1994, Snow 1996).

Teatteritaide yhdistää ainutlaatuisella tavalla lukuisia taidemuotoja: musiikkia, laulua, tanssia, tarinankerrontaa, nukkeja, maalaustaidetta, muotoilua, runoutta ja näyttelemisen taidetta. Teatterilla voidaan nähdä olevan myös sisäsyntyinen parantava vaikutus, joka perustuu sen alkuperään inhimillisen kulttuurin ytimessä (Snow ym. 2003).

Näyttelijöiden terveydestä on kuitenkin tehty vain niukasti tutkimusta. Kyaga ym. (2013) eivät löytäneet välittömiä yhteyksiä luovuuden ja mielenterveyden sairauksien välillä kaksisuuntaista mielialahäiriötä lukuun ottamatta.

Myös näyttelijöiden kuolleisuudesta on hyvin vähän tietoa. Marinin (1986) ammattiryhmien välisiä kuolleisuuseroja käsitelleessä tutkimuksessa näyttelijät sisältyivät samaan ryhmään toimittajien, taiteilijoiden ja muusikoiden kanssa. Vuosien 1971-1991 kuolleisuusseurannassa näyttelijöiden ja laulajien kuolleisuus oli samalla tasolla kaikkien palkansaajien kuolleisuuden kanssa (Notkola ym. 1995). Vuosien 1996-2000 (Pensola ym. 2004) ja 2001-2007 (Pensola ym. 2012) eri ammattiryhmien kuolleisuutta koskevissa tutkimuksissa näyttelijät oli yhdistetty samaan luokkaan muiden taiteilijoiden kanssa. Vuosien 19962000 seurannassa taiteilijoiden kuolleisuus oli miehillä kaikkia palkansaajia alhaisempaa ja naisilla taas samalla tasolla, kun taas ajanjaksolla 2001-2007 naisnäyttelijöiden kuolleisuus näyttäisi olleen kaikkia palkansaajia alhaisempaa, mutta miehillä kuolleisuus ei eronnut muista. (Taulukko 1.)

Myös ruotsalaisessa tutkimuksessa (SCB 2014) näyttelijät lukeutuivat samaan ryhmään toimittajien ja taiteilijoiden kanssa (ammattiluokka 245). Tämän ryhmän kuolleisuus (SMR, Standardized Mortality Ratio) vuosina 20082012 oli miehillä 92 (95 \%:n luottamusväli 71117) ja naisilla 81 (66-99) kaikkien palkansaajien kuolleisuuteen $(S M R=100)$ verrattuna.

Kulttuuri, yhteisöllisyys ja sosiaalisuus ovat yhteydessä pidempään elinikään. Näyttelijän työ on yhteisöllistä ja vuorovaikutteista. Voisiko näyttelijöiden kuolleisuus sen myötä olla muita ammattiryhmiä alhaisempaa? Tavoitteenamme on selvittää, millainen on näyttelijöiden kuolleisuuden taso muihin palkansaajiin verrattuna. 


\section{Aineisto ja menetelmät}

Tutkimuksen aineistona on Tilastokeskuksen väestölaskentatiedoista ja kuolemansyytiedoista koottu yksilötasoinen pitkittäisaineisto kaikista palkansaajista vuoden 2000 lopussa. Tutkimusväestönä ovat 25-64-vuotiaat Suomessa asuvat palkansaajat 31.12.2000. Kuolleisuutta seurataan ajalla 2001-2013. Seuranta-aika päättyy seuranta-ajan loppuun, maasta muuttamiseen tai kuolinpäivään. Tutkimuksessa käytetään vuoden 2000 lopun ammattitietoa (Ammattiluokitus 2001). Jos tieto puuttuu, käytetään vuoden 1995 ammattia.

Ammattiryhmille lasketaan erilaisen ikärakenteen vaikutuksen poistamiseksi ikävakioidut kuolleisuusluvut käyttäen suoraa ikävakiointia (SDR, Standardized Death Rate) sekä ikävakioidut kuolleisuussuhteet (SMR) ja näiden 95 prosentin luottamusvälit (Armitage ym. 2005). Vertailu- ja vakioväestönä käytetään kaikkia vuoden 2000 lopun palkansaajia.

\section{Tulokset}

Näyttelijöiden kuolleisuus oli vuosina 20012013 sekä miehillä (SMR 82) että naisilla (SMR 93) kaikkia palkansaajia hiukan alhaisemmalla tasolla (taulukko 2). Sen sijaan muihin erityisasiantuntijoihin verrattuna näyttelijöiden kuolleisuus oli hiukan korkeampaa. Erot eivät kuitenkaan olleet tilastollisesti merkitseviä. Kaikkien taiteilijoiden kuolleisuus oli miehillä samaa tasoa kaikkien palkansaajamiesten kuolleisuuden kanssa, naisilla sen sijaan mahdollisesti kaikkien palkansaajien kuolleisuutta alhaisempaa.

Näyttelijöiden kuolleisuutta verrattiin myös muihin ammattiluokkiin (taulukko 3). Näyttäisi siltä, että miehillä näyttelijöiden kuolleisuus oli korkeampaa kuin johtajilla ja erityisasiantuntijoilla. Sen sijaan asiantuntijoiden kanssa kuolleisuus oli samalla tasolla. Työntekijäammateissa oleviin verrattuna näyttelijöiden kuolleisuus oli alhaisempaa. Erot eivät kuitenkaan olleet tilastollisesti merkitseviä. Naisilla eri ammattiluokkien väliset kuolleisuuserot olivat pienempiä kuin miehillä.

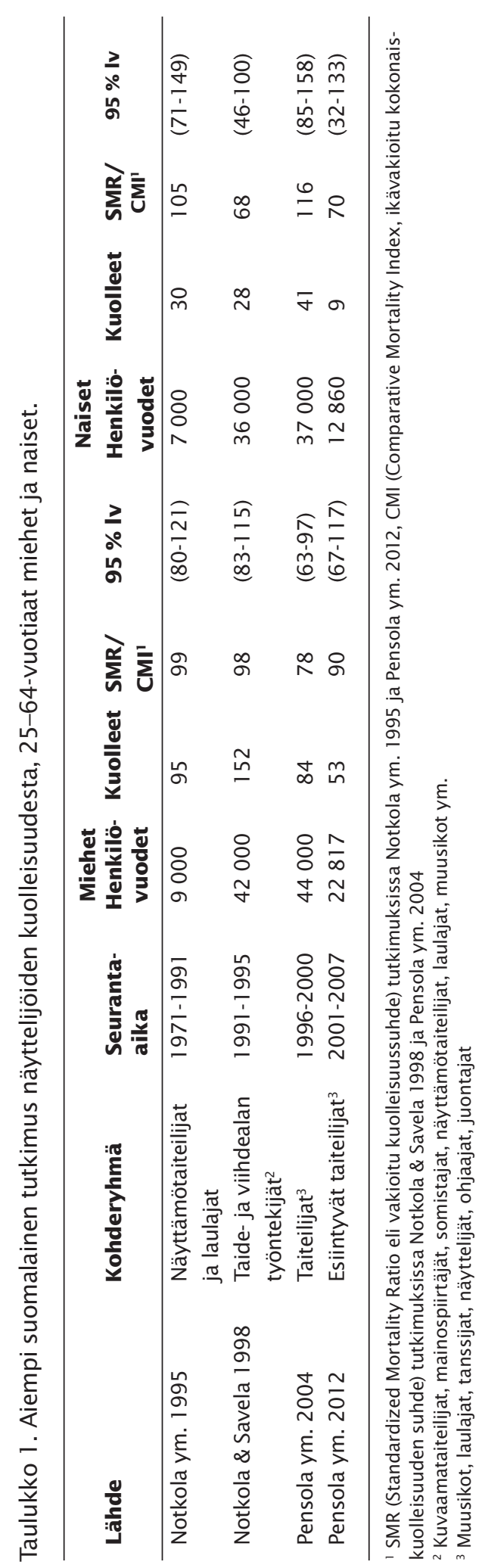

KUNTOUTUS 2 |2016 53 
Taulukko 2. Näyttelijöiden, muiden taiteilijoiden ja erityisasiantuntijoiden kuolleisuus kaikkiin palkansaajiin (SMR=100) verrattuna 2001-2013, 25-64-vuotiaat miehet ja naiset.

\begin{tabular}{|l|r|r|r|r|r|r|}
\hline Ammatti (TK:n ammattikoodi) & $\begin{array}{l}\text { Henkilö- } \\
\text { vuodet }\end{array}$ & Kuolleet & $\begin{array}{c}\text { SDR } \mathbf{~} \\
\mathbf{1 0} \mathbf{0 0 0} \mathbf{~ h v}\end{array}$ & $\mathbf{9 5}$ \% Iv & SMR $^{\mathbf{2}}$ & $\mathbf{9 5}$ \% Iv \\
\hline Miehet & & & & & & \\
Näyttelijät (24551) & 6823 & 21 & 33 & $(19-48)$ & 82 & $(54-126)$ \\
Näyttelijät ja ohjaajat (24551, 24552) & 9030 & 25 & 29 & $(17-41)$ & 74 & $(50-109)$ \\
Kaikki taiteilijat (2452) & 40839 & 138 & 37 & $(31-44)$ & 96 & $(81-113)$ \\
Kaikki viihdealan asiantuntijat (3471) & 29553 & 99 & 42 & $(33-50)$ & 106 & $(87-130)$ \\
Erityisasiantuntijat (2) & 1917798 & 4981 & 27 & $(26-28)$ & 68 & $(66-70)$ \\
Kaikki palkansaajat & 11055903 & 41871 & 39 & $(39-40)$ & 100 & \\
Naiset & & & & & & \\
Näyttelijät (24551) & 5947 & 10 & 18 & $(6-31)$ & 93 & $(50-174)$ \\
Näyttelijät ja ohjaajat (24551, 24552) & 7039 & 10 & 15 & $(5-25)$ & 79 & $(43-147)$ \\
Kaikki taiteilijat (2452) & 34710 & 37 & 16 & $(11-21)$ & 78 & $(57-108)$ \\
Kaikki viihdealan asiantuntijat (3471) & 16011 & 24 & 19 & $(11-27)$ & 107 & $(72-160)$ \\
Erityisasiantuntijat (2) & 2021577 & 3042 & 16 & $(15-16)$ & 84 & $(81-86)$ \\
Kaikki palkansaajat & 11255480 & 21838 & 19 & $(18-19)$ & 100 & \\
\hline
\end{tabular}

I SDR, Standardized Death Rate eli ikävakioitu kuolleisuusluku

2 SMR, Standardized Mortality Ratio eli vakioitu kuolleisuussuhde

Taulukko 3. Näyttelijöiden kuolleisuus (SMR) eri ammattiryhmiin verrattuna 2001-2013, 25-64-vuotiaat miehet ja naiset.

\begin{tabular}{|lccrc|}
\hline $\begin{array}{l}\text { Ammatti (TK:n ammattikoodi) } \\
\text { (SMR=100) }\end{array}$ & $\begin{array}{l}\text { Miehet } \\
\text { SMR' }^{\mathbf{1}}\end{array}$ & $\mathbf{9 5} \% \mathbf{~ I v}$ & $\begin{array}{l}\text { Naiset } \\
\text { SMR }\end{array}$ & $\mathbf{9 5}$ \% Iv \\
\hline Sotilaat (0) & 110 & $(72-169)$ & 54 & $(27-108)$ \\
Johtajat ja ylimmät virkamiehet (1) & 132 & $(86-202)$ & 106 & $(57-197)$ \\
Erityisasiantuntijat (2) & 121 & $(79-186)$ & 112 & $(60-207)$ \\
Asiantuntijat (3) & 100 & $(65-153)$ & 105 & $(57-195)$ \\
Toimisto- ja asiakaspalvelutyöntekijät (4) & 76 & $(49-116)$ & 90 & $(48-167)$ \\
Palvelu-, myynti- ja hoitotyöntekijät (5) & 75 & $(49-114)$ & 93 & $(50-173)$ \\
Maanviljelijät, metsätyöntekijät ym. (6) & 70 & $(45-106)$ & 91 & $(49-169)$ \\
Rakennus-, korjaus- ja valmistustyöntekijät (7) & 71 & $(46-108)$ & 83 & $(44-154)$ \\
Prosessi- ja kuljetustyöntekijät (8) & 68 & $(44-104)$ & 86 & $(47-161)$ \\
Muut työntekijät (9) & 59 & $(39-91)$ & 72 & $(39-134)$ \\
\hline
\end{tabular}

I SMR, Standardized Mortality Ratio eli vakioitu kuolleisuussuhde

\section{Johtopäätökset}

Näyttelijän ammatissa sosiaalisuus, kommunikaatio ja hyvä peruskunto ovat tärkeitä osatekijöitä taiteellisen työn toteutuksessa. Sosiaalinen kanssakäyminen on yhteydessä hyvinvointiin ja elämänlaatuun (Uvnäs Moberg 2000, 2009) ja elinikään (Hyyppä 2013).

Edellä mainitut seikat saattavat olla osa- syy siihen, että näyttelijöiden kuolleisuus on hieman kaikkien palkansaajien kuolleisuutta alhaisempaa. Toisaalta suhteessa muihin samantasoisiin ammatteihin näyttelijöiden kuolleisuus vaikuttaa olevan hieman korkeampaa. Ammattiryhmän koon pienuuden vuoksi tuloksista on kuitenkin vaikea sanoa mitään kovin varmaa. Näyttelijöiden kuolleisuutta tulisi- 
kin tutkia aineistolla, jossa on pidempi seuranta-aika ja joka olisi paremmin sovellettavissa näyttelijöiden terveyteen, elämänlaatuun ja elinikään yhteydessä oleviin kysymyksiin.

On kuitenkin pidettävä mielessä, että ammatin ja kuolleisuuden välinen yhteys on aina monimutkaisen tapahtumaketjun lopputulos, ja siten eri ammatteihin tai niissä pysymiseen voi myös valikoitua henkilöitä terveydentilan tai siinä tapahtuvien muutosten mukaan. Lopuksi on vielä todettava, että kuolleisuus edustaa vain yhtä, vaikkakin keskeistä terveyden osa-aluetta, ja siten olisi myös mielenkiintoista suunnata samanlaista vertailevaa tutkimusta muiden terveyden osa-alueiden, kuten vaikkapa toimintakyvyn, alueelle.

Hanna Rinne, VTM, tutkija, Kuntoutussäätiö

Johan Storgård, MA, teatterinjohtaja, Svenska Teatern

Sakari Suominen, LT, professori, Skövden korkeakoulu ja Turun yliopisto

\section{Lähteet}

Ammattiluokitus (2001) Ammattiluokitus 2001. Tilastokeskus, Helsinki.

Armitage P, Berry G, Matthews JNS (2005) Statistical Methods in Medical Research. Fourth Edition. Blackwell Publishing, UK

Bygren LO, Konlaan BB, Johansson SE (1996) Attendance at cultural events, reading books or periodicals, and making music or singing in a choir as determinants for survival: Swedish interview survey of living conditions BMJ 313, 1577.

Dalgard O S, Lund Håheim L (1998) Psychosocial risk factors and mortality: A prospective study with special focus on social support, social participation, and locus of control in Norway. J Epidemiol Community Health 52, 476-81.

Emunah R (1994) Acting for Real: Drama Therapy, Process, Technique, and Performance. Brunner-Routledge, New York \& London.

Glass T A, Mendes de Leon C, Marottoli R A, Berkman L F (1999) Population based study of social productive activities as predictors of survival among elderly Americans. BMJ 319, 478-83.

Hyyppä MT, Liikanen HL (2005) Kulttuuri ja Terveys. Edita Publishing Oy, Helsinki.

Hyyppä MT (2013) Kulttuuri pidentää ikää. Kustannus Oy Duodecim, Helsinki.

Johansson SE, Konlaan BB, Bygren LO (2001) Sustaining habits of attending cultural events and mainteinance of health: a longitudinal study.
Health Prom Intern 16, 229-34.

Konlaan BB, Bygren LO, Johansson SE (2000) Visiting the cinema, concerts, museums or art exhibitions as determinant of survival: a Swedish fourteen-year cohort follow-up. Scan J Public Health 28, 174-8.

Kyaga S, Landén M, Boman M, Hultman CM, Långström N, Lichtenstein P (2013) Mental illness, suicide and creativity: 40-Year prospective total population study. Journal of Psychiatric Research 47, 1, 83-90.

Marin R (1986) Ammattikuolleisuus 1971-80. Tutkimuksia Nro 129. Tilastokeskus, Helsinki.

Notkola V, Pajunen A, Leino-Arjas P (1995) Telineet, tehdas vai toimisto - tutkimus ammattiryhmittäisestä kuolleisuudesta ja työkyvyttömyydestä. SVT Terveys 1995:4. Tilastokeskus, Helsinki.

Notkola V, Savela S (1998) Ammattiryhmittäinen kuolleisuus Suomessa 1991-1995. Työterveyslaitos, Tilastokeskus, Helsinki.

von Otter C (2008) Kultur - en del av ett hälsosamt liv? Kulturrådets skriftserie 4. Statens kulturråd, Stockholm, 1-31.

Pensola T, Ahonen H, Notkola V (2004) Ammatit ja kuolleisuus. Työllisten ja työttömien ammattiryhmittäinen kuolleisuus 1996-2000. Kuntoutussäätiö, Tilastokeskus, Helsinki.

Pensola T, Shemeikka R, Kesseli K, Laihiala T, Rinne H, Notkola V (2012) Palkansaaja, yrittäjä, työtön. Kuolleisuus Suomessa 2001-2007. Kuntoutussäätiö tutkimuksia 84, Helsinki.

SCB (2014) Yrke och dödlighet 2008-2012. Demografiska rapporter 2014:3. Statistiska centralbyrån, Stockholm.

Snow S (1996) Focusing on mythic imagery in brief drama therapy with psychotic individuals. Teoksessa A. Gersie (toim.) Dramatic approaches to brief therapy. Jessica Kingsley, London, 216-235.

Snow S, D’Amico M, Tanguay D (2003) Therapeutic theatre and well-being. The Arts in Psychotherapy $30,73-82$.

Uvnäs Moberg K (2000) Lugn och Beröring - oxytocinets läkande verkan i kroppen. Natur och Kultur Akademisk, Stockholm.

Uvnäs Moberg K (2009) Närhetens hormon: oxytocinets roll i relationer. Natur och Kultur Akademisk, Stockholm.

Wilkinson A V, Waters AJ, Bygren LO, Tarlov AR (2007) Are variations in rates of attending cultural activities associated with population health in the United States. BMC Publ Health 7, 226-31.

Willcox DC, Willcox BJ, Sokolovsky J, Sakihara S (2007) The cultural context of "successful aging" among older women weavers in a northern Okinawan village: The role of productive activity. J Cross Cult Gerontol 22, 137-65. 